\title{
Comunicación

\section{Dragon Ball Z y Los Simpson: propuestas axiológicas en la televisión para la conformación de la vida política de la comunidad infantil}

ARMANDO M. IBARRA LÓPEZ 1

Y YADIRA ROBLES IRAZOQUI ${ }^{2}$

Este artículo presenta el resultado de un análisis axiológico realizado en el espacio audiovisual de Guadalajara con la finalidad de conocer los significados simbólicos políticos de dos series televisivas infantiles: Dragon Ball Z y Los Simpson. Se analiza el comportamiento político de los personajes de ambas series dentro de las organizaciones sociales, esto como una propuesta simbólica que provee a los niños, en su papel de agentes sociales, significados referentes al poder y el liderazgo, a las disfunciones sociales y a la corrupción política, así como a los Derechos Humanos y a la justicia social.

Palabras ClaVE: socialización política, programas televisivos, recepción televisiva, valores.
This article presents the results of an axiological analysis which was carried out with the purpose of exploring the political symbolic meaning of two television series for children: Dragon Ball $Z$ and The Simpson. The political behavior of the characters of both series is analyzed within social organizations. This is done as a symbolic proposal that provides the kids, in their role as social agents, meanings referring to power and leadership, to social disfunctions and political corruption, as well as Human rights and social justice.

KEY WORDS: political socialization, television programs, television reception, values.

1 Profesor Investigador de la Universidad de Guadalajara.

Correo electrónico: armandoibarra60@hotmail.com.

2 Profesora de la Universidad del Valle de Atemajac.

Correo electrónico: y.roblesi@univa.mx 


\section{INTRODUCCIÓN}

La relación entre medios de comunicación, cultura y comportamiento infantil ha sido abordada desde diversos campos de estudio; bajo perspectivas teóricas distintivas de cada área se han ofrecido diversas explicaciones acerca del tejido conformado por instancias y agentes sociales, así como de la forma en que éstos participan durante la elaboración de la explicación que los niños construyen acerca del mundo social en que se desenvuelven.

La televisión, como medio favorito de los teóricos de la comunicación para realizar sus estudios y de los niños para disfrutar de su tiempo libre, ha sido vinculada de diversas formas a los procesos de descubrimiento y comportamiento del mundo de los sujetos, adquiriendo papeles teóricos que van desde la "manipuladora de mentes infantiles" hasta la "ofertadora de signos para la construcción simbólica de las comunidades infantiles" y provocando un sinfin de propuestas acerca de la relación entre medios y audiencias.

En este artículo se presentan los resultados de un estudio acerca de las propuestas de significados políticos de dos series televisivas de gran aceptación infantil, Los Simpson y Dragon Ball Z; esto como vertiente de una investigación más amplia realizada acerca del consumo televisivo y la socialización política de los escolares de la Zona Metropolitana de Guadalajara (Ibarra, 2003).

Se ha dividido la información en cuatro apartados: el de la argumentación teórica, el de las aclaraciones metodológicas, el de contextualización de los programas analizados y el de los resultados. La finalidad de ello es proponer un entramado teórico-metodológico-reflexivo que permita rescatar la importancia de analizar los contenidos televisivos como propuestas informativas para la conformación de conceptos sociales, en este caso el de política, y para la socialización política.

\section{LOS MENSAJES TELEVISIVOS Y}

LA PARTICIPACIÓN DEL NIÑO COMO AGENTE SOCIAL

La intencionalidad de este artículo no es presentar una evaluación teórica acerca de la participación de la televisión en las conductas infantiles, 
ni tampoco un acercamiento reflexivo sobre la construcción de estructuras sociales y axiológicas a partir del uso de la información mediática; pese a ello, es pertinente aclarar que partimos de la concepción de la Televisión como un espacio simbólico (Bourdieu, 1997) que ofrece a los niños significados comunes a los que manejan cotidianamente y propuestas simbólicas novedosas que facilitan la identificación de algunos elementos y la incorporación de información nueva a la obtenida anteriormente desde otras instancias.

Se cree que la información venida de la televisión sirve a los niños, en menor o mayor medida según sus contextos socioculturales, como un elemento significativo para la elaboración de mecanismos de conducción social, moral y política dentro de una estructura en constante interpretación y reconstrucción y que es generada por ellos mismos y por sujetos mayores que ellos.

A través de la vida social, el niño adquiere un marco de referencia para interpretar las experiencias; durante su vida cotidiana, ellos aprenden a negociar los significados de forma congruente con las demandas de la cultura -sean éstas políticas, morales, sociales o económicas- y adquieren los elementos necesarios para influir en la movilización de las estructuras sociales y para convertirse en un agente social, condición que también le permitirá la posibilidad de participar en la reestructuración de su mundo.

A partir de su capacidad de obrar, entendida ésta "no como la intención que la gente tiene para hacer cosas, sino como la capacidad de hacer esas cosas", sean o no intencionales (Giddens, 1995:46), y mediante el registro reflexivo de dicha capacidad, los niños toman en cuenta su actuación y la actuación de los demás, incluso la de los personajes televisivos, al momento de poner en práctica un acontecer.

Como resultado de ese obrar, que convierte a los niños en agentes sociales, provocan consecuencias buscadas y consecuencias no buscadas y dan nacimiento a la llamada dualidad estructural, concepto que ha servido para explicar "las propiedades articuladoras que consienten la ligazón de un espacio tiempo en sistemas sociales: las propiedades por las que se vuelve posible que prácticas sociales que discerniblemente existan a lo largo de segmentos variables de tiempo y de espacio, y que presten a éstos una forma sistémica" (Giddens, 1995:54). 
Mediante las acciones cotidianas, y según el medio se los exija, los niños llegan a elaborar dispositivos sociales para conducirse en sociedad. De esta manera logran satisfacer las necesidades inmediatas que provocaron esas acciones, a la vez que alimentan una estructura sobre el significado y la axiología de acciones ya existente.

Los significados que el niño tiene acerca del mundo social, sumados a aquéllos que está adquiriendo a partir de diferentes instancias sociales como la televisión, le son útiles para movilizar estructuras sociales y axiológicas de su entorno mediato e inmediato. Si el niño es capaz de realizar tal acción movilizadora, y para hacerlo parte de la información que ha recabado de diversas fuentes mediáticas, entonces es importante estudiar los mensajes televisivos como información que podrá ser o no ser retomada por los niños en el proceso de explicación de su sociedad; los mensajes televisivos, como propuestas simbólicas, pueden dirigir, o mínimamente sugerir la significación de lo axiológico y de lo social.

\section{LA AXIOLOGÍA POLÍTICA COMO GUÍA}

\section{PARA EL ESTUDIO DEL TEXTO TELEVISIVO}

El análisis axiológico es una forma de acercarnos a los significados que presenta el texto televisivo, pues son los valores, "más que las actitudes o las simples conductas, los que reflejan la racionalidad detrás de ciertas acciones que eventualmente facilitarán escudriñar lo que Giddens ha denominado la agencia humana" (Orozco, 1993:18).

Los valores expresan el significado de la vida social y de las relaciones humanas de quien los produce; es la propuesta que consciente o inconscientemente formula un grupo de emisores o creadores a partir de un texto que se materializa en un programa televisivo específico y que de alguna manera representa una oferta de significados para la construcción de la concepción axiológica y social de quienes los consumen.

Las propuestas axiológicas o de significados presentes en el texto televisivo son resultado de una producción social elaborada por diversas compañías de diferentes nacionalidades, donde hegemónicamente, y para los últimos tiempos, se encuentran las provenientes de Estados Unidos de Norteamérica (EUA) y Japón (Sánchez, 1995, 1997; Alonso, Matilla y Vázquez, 1995). Sin olvidar las de origen europeo, que si bien se enfo- 
can más bien a un público diferente al infantil, no dejan de tener contacto con éste.

Los valores, para algunos autores (Enlace, 1998), son significados o concepciones acerca del ser humano, la naturaleza, el mundo y el cosmos; se operacionalizan a partir de hábitos, actitudes y acciones de los sujetos en la vida cotidiana, de tal suerte que el conocer las propuestas de significados traducidos en valores es acercase a la esencia misma de los modelos culturales. El texto televisivo, como uno de los formatos mediáticos más adecuados para la transmisión de valores, se convierte actualmente en la forma más sofisticada de la participación televisiva como agente de socialización representativa de nuestra época.

Cada vez más en los estudios de socialización en general, y política en particular, se afinan y redefinen los acercamientos metodológicos con propuestas que van directamente a los significados que entran en lucha por la hegemonía de las estructuras de significación social (Giddens, 1995). El entender los significados y valores que propone la programación televisiva nos acerca a una de las perspectivas del marco simbólico que constituye las culturas.

Los valores que se proponen en las dos series o comedias caricaturizadas seleccionadas para este estudio señalan algunas pistas de la oferta sígnica-axiológica que la TV ofrece a la comunidad infantil. En México, cuando menos hasta 1993 y acorde a los hallazgos de Guillermo Orozco (1993), los dibujos animados y los programas de aventuras son los géneros donde se aprecia mayor variedad en las propuestas axiológicas mediatizadas.

La comedia caricaturizada, al ser mayoritariamente extranjera, conlleva un tipo de valores muy propios de la cultura desde donde se generaron. Es decir, al importar un programa televisivo de otro país se transfiere un grupo de valores que constituyen ideologías y estructuras de significados distintos a nuestro entorno.

El enfoque de este análisis no tendrá en cuenta determinados aspectos -sin duda relevantes como lo que a nosotros nos ocupa- implicados en esta penetración de programas importados, como son, por ejemplo, los que afectan el desarrollo de la industria audiovisual nacional y el intercambio internacional (Sánchez, 1995:1997). La perspectiva que ahora nos ocupa apunta exclusivamente a detectar la propuesta de valo- 
res políticos de los dos programas más vistos por los escolares de la Zona Metropolitana de Guadalajara.

\section{ACLARACIONES METODOLÓGICAS}

Como ya se mencionó antes, las reflexiones presentadas en este artículo forman parte de una investigación más amplia sobre $T V$ y socialización política infantil; en esta ocasión sólo se presentan los resultados derivados del análisis axiológico y de contenido de los programas de Dragon Ball Z y Los Simpson, encaminado a la identificación y análisis de las propuestas axiológicas.

La selección de los programas analizados obedece a los gustos y preferencias de 652 escolares de la Zona Metropolitana de Guadalajara (Guadalajara, Zapopan y Tlaquepaque) durante el año 2000, tiempo en el que se levantó información para el estudio de la socialización política vinculada a la televisión, incluyendo en ésta la concerniente a los gustos y hábitos televisivos de los niños (Ibarra, 2003).

A pesar de que los dos primeros lugares otorgados por los niños a los programas "favoritos" para la recepción infantil son Dragon Ball Zy Pokemon, se decidió hacer el análisis a partir de los contenidos del primero y de Los Simpson, bajo el criterio de la no repetición del origen de cada uno de los productos y la inquietud de conocer las propuestas axiológicas para la vida política realizadas desde culturas diferentes.

De esta manera, la nacionalidad de los programas coincide con el lugar de origen de los programas que en ese momento estaban presentando mayor auge dentro de los mercados de la industria cultural. ${ }^{3}$ Los Simpson, clasificado dentro del género de comedia, es de procedencia estadounidense y Dragon Ball Z, clasificado como serie caricaturizada, es de origen japonés. El primero con más de 10 años de transmisión a la

\footnotetext{
3 La década de los noventa pasará a la historia como la etapa en que el Hollywood televisivo, junto con la producción televisiva Japonesa, arrojaron una buena cosecha de títulos infantiles y juveniles que hoy ya son clásicos. En Estados Unidos, Friends, Frasier, Seinfeld, Los Simpson y en Japón Ranma y medio, Dragon Ball, y Dragon Ball Z, extendiendo su influencia más allá del propio género y creando el escenario para la transmisión de la cultura propia de cada país.
} 


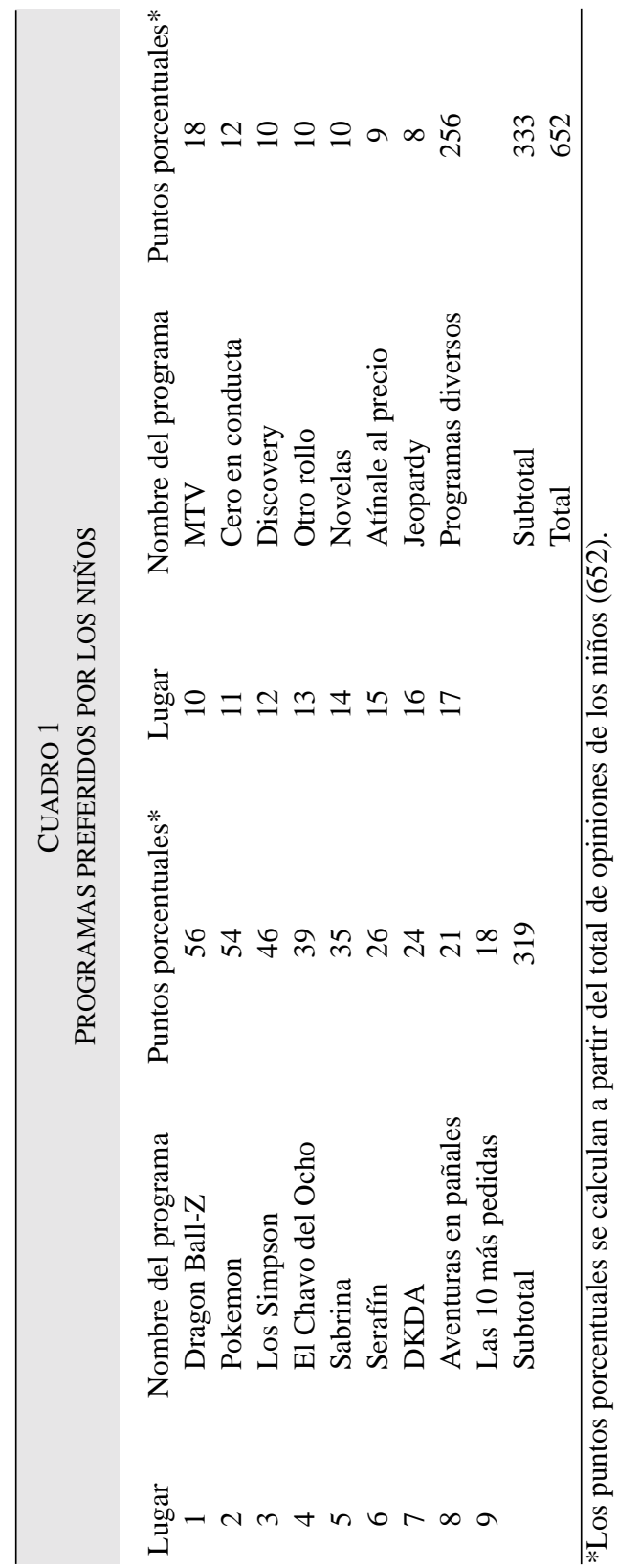


fecha del levantamiento de información para el estudio (año 2000), y el segundo poco menos de 10 años de circulación para las mismas fechas.

Ahora bien, el análisis del contenido de los programas se realizó bajo el entendido de que los mensajes televisivos son polisémicos y se pueden abordar desde diferentes puntos de vista y mediante diversos instrumentos, de tal manera que la elección del método de análisis puede definir diferentes enfoques que producen diferentes imágenes del objeto que se está estudiando. Al respecto, el método de análisis de contenido corre el riesgo de provocar interpretaciones diferentes de quienes produjeron los textos; sin embargo, ésta es una posibilidad que no sólo vive el analista, sino también el propio consumidor de los mensajes televisivos, quien puede o no vivir una interpretación similar a la esperada por el productor de los discursos.

El análisis de contenido procura comprender datos, más que como acontecimientos físicos, como fenómenos simbólicos que representan imágenes, discursos, referencias, valoraciones e intenciones de individuos o grupos sociales en los procesos de comunicación humana (Krippendorff, 1997). Este método, más que continuar con la tradición de sólo enumerar palabras importantes, debe responder a la tarea de analizar los signos como fenómenos simbólicos, reconociendo su papel social y sus significados axiológicos en las poblaciones, en este caso la infantil.

Así, el análisis de contenido lo entendimos en este trabajo como un método de recopilación que ayudó a analizar el contenido valoral y de significados políticos manifestados en los mensajes discursivos del texto televisivo de la programación seleccionada.

La herramienta de análisis que se tomó en cuenta para este trabajo se adscribiría a la clasificación de Berelson (1952) para reflejar actitudes, intereses y valores -pautas culturales- de ciertos grupos de la población, propuestos por medio de personajes, mensajes e imágenes creados para satisfacer un patrón cultural (ver Cuadro 2).

Se cree que no siempre existe coincidencia acerca de los significados de los mensajes producidos por los agentes que participan de ellos, por lo que en este trabajo preferimos no hacer inferencias de carácter lingüístico, limitándonos a puntualizar situaciones observadas en los personajes que nos permitieron entender, en su contexto específico, el significado de los mensajes audiovisuales dentro de un marco social de valores. 


\section{CUADRO 2}

FORMATO UTILIZADO PARA EL ANÁLISIS DE CONTENIDO

\begin{tabular}{l|l} 
Programa: & Duración: \\
\hline Género: & Puntaje rating: \\
\hline Tema: & Procedencia: \\
\hline
\end{tabular}

Breve descripción de principales personajes:

Personaje 1 Personaje 2 | Personaje 3

Estilo de autoridad presentada por personajes: (autoritario-democrático)

Personaje 1 Personaje 2 Personaje 3

Principales valores de personajes: $\quad$ Principales actividades de personajes: \begin{tabular}{l|l|l|l|l|l|} 
Personaje 1 & Personaje 2 & Personaje 3 & Personaje 1| Personaje 2 & Personaje 3 \\
\hline
\end{tabular} Principales valores en el discurso: $\quad$ Principales actividades en discurso:

Procedimiento que siguen personajes (patrones) para alcanzar fines / objetivos / valores

Escenario (descripción):

Principales aprendizajes:

\section{ACERCA DE LOS PROGRAMAS ANALIZADOS}

Ambos programas son tradición televisiva. Los Simpson representan "la única reivindicación de la comedia televisiva que se ha conocido en los últimos años" (Álvarez, 1999:122) y el punto de partida de una concepción distinta de la comedia. Dragon Ball Z, sin ser comedia, abraza el mismo esquema en cuanto a las relaciones entabladas durante la trama, pero con una estructura más compleja entre sus personajes. Ambos programas presentan diferentes planteamientos y estructuras a partir del origen de sus creadores y productores; ambos traen consigo propuestas simbólicas, axiológicas y conceptuales representativas de diferentes culturas.

\subsection{Los Simpson}

El contexto de Los Simpson, concebido por Matt Groening y producido por Gracie Films para Twentieth Century Fox y Fox Network en 1987, es la parodia y la sátira con efectos cómicos en un neofamilialismo con- 
temporáneo y típicamente estadounidense; es una comedia que establece un puente entre los viejos públicos y la nueva generación de la computadora, el internet y el videojuego.

En el contenido de la serie se concibe a la familia Simpson como una familia peculiar. Un hijo cuya única aspiración es crear conflictos; una hija poco común y sumamente crítica; una esposa con una sangre tan fría que por muchos problemas que le dé la familia nunca se enfada; un padre de familia excepcional: vago, inculto y alcohólico; la única que parece salvarse es la pequeña Maggie, quizá porque al ser la bebé de la familia no ha aprendido a emitir palabra. A pesar de las personalidades de cada uno de los integrantes de esta polémica familia, sobresalen el cariño y el amor familiar.

\subsection{Dragon Ball Z}

Dragon Ball Z es la segunda parte de la serie basada en el popular manga japonés ${ }^{4}$ creado por Akira Toriyama. A esta historia le antecede la de Dragon Ball y le procede la de Dragon Ball GT, tres historias que guardan congruencia estructural, axiológica y significativa entre sí, aunque cada una de ellas puede ser apreciada, disfrutada y analizada de manera independiente. La saga de Dragon Ball Z narra el momento en que Goku conoce su origen y se enfrenta al peor enemigo de su raza. Se inicia 5 años después del fin de Dragon Ball y para entonces Goku y su pareja Chi Chi, han tenido un hijo al que le han puesto por nombre Gohan.

La historia de Dragon Ball $Z$ se encuentra llena de aventuras por una continua lucha contra la maldad de los personajes que ansían apoderarse de las Esferas del Dragón y, con ello, del Poder del Universo. La mayoría de las veces, Goku y sus amigos, defensores del bien, resultan vencedores de las batallas; sin embargo, llega el momento en que Goku es conquistado por la muerte que le provoca su propio hermano Raditz, un ser malvado y ambicioso que también muere junto con Goku, no sin antes confesarle a los amigos de éste que es posible resucitarlo si reúnen

4 Producciones audiovisuales artísticas y tecnológicas de dibujos animados elaborados por jóvenes caricaturistas japoneses que combinan la computación, la electrónica, el ingenio y la creatividad. 
las Esferas del Dragón. Al resucitar a Goku se continúa con peleas que hacen del personaje de Dragon Ball $Z$ un poderoso luchador con más enemigos. Pero llega el día en que gran parte del equipo de Goku muere en uno de los más fuertes enfrentamientos, la batalla contra Cell; la mayoría de ellos logran ser resucitados, menos Goku, quien ya había hecho uso de este poder y ahora tendrá que conformarse con viajar y permanecer por cierto tiempo en la tierra.

Dragon Ball $Z$ rompe con la estructura de la dicotomía occidental para encarnar a personajes terrestres y extraterrestres, ilógicos, irracionales y sensitivos que conviven y pelean por la hegemonía del universo en un continuum por el espacio y el tiempo. Aquí, pasado, presente y futuro, generaciones y razas distintas, explican la trama a partir de una lógica del caos. Desde una perspectiva dialéctica, por la presencia del pasado existe el presente y sin éste no habría futuro, y ni siquiera el pasado mismo; el futuro por su parte, guía al presente y por ende al pasado. Por otra parte, el género y la sexualidad, el mal y el bien, Satanás, los demonios y la casta de guerreros, están implicados en personajes que cambian de un estatus a otro. El entorno de Dragon Ball Z es menos familiar, más futurista, tenebroso e irreal.

\subsection{Los Simpson y Dragon Ball Z: adiós a los viejos tiempos televisivos}

Programas como los seleccionados para este análisis marcan la ruptura entre los viejos y los nuevos contenidos, las antiguas y las innovadoras estructuras y propuestas simbólicas televisivas; Los Simpson y Dragon Ball $Z$ son una muestra de la nueva ola de contenidos intertextuales y dicotómicos. Para distintos portavoces y críticos de la "cultura audiovisual joven", los nuevos dibujos animados señalan una ruptura generacional equivalente a la que se produjo en los años cincuenta entre los bailes de salón y el rock (Álvarez, 1999).

Producciones japonesas como Dragon Ball Z, además de coincidir con el concepto de los programas de estos nuevos tiempos, cuenta con personajes más ambiguos, ilógicos, irracionales y sensitivos. La trama de los diferentes episodios y de la serie en general es caótica y no responde a líneas argumentales como las que presentan Los Simpson o muchas de las series a las que estamos acostumbrados. 


\subsection{Los Simpson y Dragon Ball Z: una reflexión inicial sobre sus contextos televisivos y sus estructuras narrativas}

Los programas y las series televisivas en formato de comedia caricaturizada provenientes de EUA y Japón parecieran manejar estructuras parecidas, pero tienen diferencias de fondo en algunos aspectos técnicos de formato, como la conexión entre los capítulos y los fragmentos de cada programa (Contreras y García, 1979), sin olvidar aspectos referentes a los contenidos y a las propuestas ideológicas que realizan. La diferencia entre los textos que utilizan los programas televisivos de ambos países parece clara. Las series de EUA cada vez más tienden a desaparecer los límites y diferencias entre el lenguaje publicitario y el lenguaje del programa, ${ }^{5}$ los japoneses han mantenido su estructura de entretenimiento con el uso de un lenguaje exclusivo dentro del texto televisivo. La interferencia de la publicidad en los relatos televisivos es una fuente importante de confusión para el buen entendimiento de sus contenidos por parte de los niños y las niñas espectadores" (Alonso, Matilla y Vázquez, 1995:157).

En breve, se puede decir que los programas del género de comedias caricaturizadas en este tipo de texto televisivo se conforman por los siguientes elementos:

- Los contenidos de los programas cuentan con temáticas casi siempre emanadas de problemáticas actuales y futuras de la realidad.

- Los programas manejan mecanismos de proyección afectiva y melodramática.

- Los dibujos animados son producto de la realidad y la fantasía, dando como resultado personajes tales como animales antropomórficos o seres humanos mutantes (Alonso, Matilla y Vázquez, 1995).

- Existe una coincidencia entre la estructura narrativa de los spots publicitarios y de los programas.

Los programas seriados, como Los Simpson, aparecen como texto televisivo dividido en pequeños fragmentos, períodos o acts de 10 minutos, los cuales sirven de entrada a las cuñas publicitarias. Además de acortar los tiempos entre cada acto, la publicidad aparece dentro de la misma trama, publicitando productos que utilizan o consumen los propios personajes. 
- Los programas manejan un formato de rápidos cambios de ritmos en los planos de la fotografía, con una velocidad superior al de la película cinematográfica y muy parecida a la de la publicidad (Contreras y García, 1979).

La combinación de los elementos anteriores dentro del texto televisivo constituye un avance importante en cuanto al manejo psicológico y sociológico de las propuestas de significados, conceptos y patrones de comportamiento construidos (Kubey y Csikszentmihalyi, 1990: Veyrat y Dayan, 1997).

\section{RESULTADOS: COMPORTAMIENTOS Y VALORES ESENCIALES Y POLÍTICOS EN LA VIDA DE LOS PERSONAJES DE LOS SIMPSON Y DRAGON BALL Z}

Suponer que cualquier tipo de programa televisivo propone de manera racional, organizada y planificada un conjunto de significados o valores específicos para formar o socializar a grupos determinados de personas, tales como los niños, es colocarnos en posturas maquiavélicas e indagadoras de esquemas televisivos cuasi fascistas acerca del control de los individuos en una sociedad.

Debe quedar claro que la televisión, como instancia social que se suma a un listado de otras previamente establecidas, como lo son la familia, la Iglesia, la comunidad y la escuela, no desempeña un papel protagonista en la vida social de los niños ni en la construcción de los conceptos que éstos realizan alrededor de ella. Se torna imposible pensar que los mensajes televisivos imprimen, por sí solos, el sentido que va a tener la sociedad en cuestiones tan polémicas como las referentes a lo axiológico y a lo político. Tampoco se puede hablar de la televisión como una instancia social de naturaleza homogénea, pues sus mensajes y la participación que éstos van a tener en diferentes grupos sociales dependerán también de los formatos utilizados para su difusión y de los géneros dentro de los cuales pueden ser catalogados.

Dicho esto, habrá que entender los siguientes resultados como propuestas reflexivas surgidas del análisis de dos series de televisión que proponen un conjunto de significados y axiologías desde una perspecti- 
va de "género como estrategia de comunicabilidad", tal como lo plantean Alonso, Matilla y Vázquez (1995), Fabian (1997), Buonanno (1999) y Orozco (1993).

"El género televisivo define el tipo de valores apropiados para ser recreados en cada tipo de programa" (Orozco, 1993:18); la propuesta de significados varía según el formato del texto televisivo en el cual aparecen. Desde luego que para un entendimiento integral habrá que considerar también los contextos ideológicos desde donde fueron creados, la proximidad cultural de los países implicados (Buonanno, 1999) y las diferentes estructuras y técnicas utilizadas para la elaboración del texto televisivo.

Los resultados encontrados durante el estudio de las propuestas simbólicas de Dragon Ball Zy Los Simpson, bajo el marco de lo axiológico, se dividen en tres grandes apartados: el de los valores esenciales de la vida social, el de los valores exclusivos del campo político y el de los comportamientos políticos de los personajes principales de cada serie. Tal división obedece a la intención de figurar las propuestas televisivas referentes al tema de interés desde un marco que vaya de lo contextual a lo específico y busca respetar la lógica de una práctica hermenéutica que considera los contextos de creación de los discursos mediáticos.

\subsection{Los valores esenciales: marco de la vida política}

Los valores esenciales manifestados en los discursos y acciones de los personajes de las dos series analizadas presentan una peculiar diferencia: en el caso de Los Simpson se refieren a situaciones cotidianas, mientras que en Dragon Ball $Z$ se hace referencia a eventos fuera de este mundo, situaciones abstractas y apartadas de la realidad.

Los valores generales de Los Simpson se caracterizan por ser de carácter individual y sólo muy pocos de participación grupal, muy adecuados al modelo de familia neoliberal que representa y critica; sin embargo, la familia es el concepto y el valor que aparece repetidamente con un enfoque muy positivo, desde éste se centran los demás valores generales. Por ejemplo, a pesar de las vicisitudes identificadas en las diferentes tramas, la familia de Los Simpson siempre salía avante debido al apoyo mutuo entre los miembros y a las muestras de cariño y amor existentes entre los personajes. 
Por su parte, lo sobrenatural, como escenario esencial de los personajes de Dragon Ball Z, genera ambientes que permiten eventos fuera de la realidad, donde los diversos seres de la trama se transforman, cambian de cuerpos y se encarnizan en luchas donde la resucitación y los viajes hacia el presente y el futuro forman parte de sus vidas. Los espacios que se reproducen en los diferentes programas denotan ambientes lúgubres y obscuros y lugares iluminados pero sin sol, cuando menos del que conocemos. Aquí se conjugan valores positivos y negativos de manera dicotómica, tales como la amistad y la ayuda al prójimo con la violencia y la lucha, todo integrado en cada uno de los sujetos.

Los valores esenciales de ambos programas difieren entre sí en lo concerniente a su significado, permeados por dos visiones de diferentes países, de hemisferios distintos: una representa el occidente y la otra el oriente, cada una con su concepción del mundo y del ser humano. Cada una con un discurso ideológico subyacente en el texto televisivo que reproduce casual o intencionalmente con un tipo de valores que en ocasiones se aceptan y en otras se niegan o silencian.

Dentro de la concepción familiar de la vida de Los Simpson se explicitan de manera muy occidentalizada algunos valores que se ejemplifican, sobre todo en los personajes protagonistas, haciendo énfasis en su expresión más individual que grupal.

Son 11 los valores identificados en el análisis de contenido de los programas seleccionados: ayuda al prójimo, amistad, superación personal, amor, diversión, pereza, desobediencia, despreocupación, mentira, sacrificio y violencia (ver Cuadro 3).

Cada uno de los valores se articula y opera mediante emociones y actividades representadas por los dibujos animados mediante movimientos faciales y del cuerpo.

La propuesta axiológica que se explicita en los programas analizados se equilibra de manera maniquea entre valores y antivalores. La finalidad del valor se expresa en las acciones de los personajes, se identifica la propuesta axiológica con una posición positiva o negativa, según sean los casos en donde se impliquen las emociones o actividades que reflejen las posturas de los personajes y tomando como punto de partida la lógica de los lineamientos morales y consuetudinarios (ver Cuadro 4). 


\section{CUADRO 3}

CONCEPTUALIZACIÓN DE LOS VALORES ESENCIALES DE LOS SIMPSON

Valor

Ayuda al prójimo

Amistad

Superación personal

Amor

Diversión

Pereza

Desobediencia

Despreocupación

Mentira

Sacrificio

Violencia
Forma en que se presenta

Repetidamente los personajes hacen algo por alguien más, ya sea un vagabundo, un familiar, un amigo o un compañero de la escuela o el trabajo.

Se refiere a actos de convivencia y relaciones agradables entre los protagonistas y otros personajes de diferentes ámbitos, reproducidos en ambientes como los paseos, los juegos y otras diversiones.

El estudio, el trabajo y el esfuerzo en lo que se hace, en las actividades de la vida cotidiana o en aquéllas que favorecen la mejora de la apariencia física.

Presente en acciones o demostraciones de afecto, situaciones de significado un tanto sexuales que se realizan entre el matrimonio Simpson (Homero y March) y en frases pronunciadas por los miembros de la familia y sus amigos.

Sobre todo en la celebración de días festivos, en los paseos familiares o en los juegos de la escuela.

Actitud de flojera de los personajes, donde se ponen a descansar o acostarse durante el día, así como comportamientos de ciertos personajes que desperdician su tiempo viendo la TV y tomando cerveza.

Acciones encaminadas a desobedecer a la autoridad, las reglas o los espacios formales, tales como la escuela, el hogar y la oficina.

Momentos en que la filosofía de vida de algunos personajes puede resumirse en hacer lo que venga en gana. Surge casi siempre en busca del bien; es decir, se ocultan cosas pero casi siempre se hace para proteger una buena causa.

Muestras de cariño en las que alguno de los personajes se da a los demás.

Sobre todo a manera de crítica de los programas televisivos. Casi siempre se da cita la violencia a través de los programas de TV que los personajes acostumbran ver. 


\begin{tabular}{|c|c|c|c|c|c|}
\hline \multicolumn{6}{|c|}{$\begin{array}{c}\text { CUADRO } 4 \\
\text { LOS VALORES ESENCIALES DE LOS SIMPSON }\end{array}$} \\
\hline Valores & ndividual & Grupal & $(+)$ & $(-)$ & $\begin{array}{c}\text { Emociones o actividades } \\
\text { que los reflejan }\end{array}$ \\
\hline La familia & & $*$ & $*$ & & Cooperación, amor \\
\hline Ayuda al prójimo & $*$ & $*$ & $*$ & & Aроуо \\
\hline Amistad & & $*$ & $*$ & & Simpatía, cariño \\
\hline La superación personal & $*$ & & $*$ & & Mejoramiento personal \\
\hline Pereza & $*$ & & & $*$ & Flojera \\
\hline Amor & $*$ & $*$ & $*$ & & Cariño, atracción y apoyo \\
\hline Desobediencia & $*$ & & & $*$ & $\begin{array}{l}\text { Actos en contra de la } \\
\text { autoridad }\end{array}$ \\
\hline Despreocupación & $*$ & & & $*$ & Actitudes nihilistas \\
\hline Diversión & $*$ & $*$ & $*$ & & $\begin{array}{l}\text { Celebración } \\
\text { Alegría }\end{array}$ \\
\hline Mentira & $*$ & & & $*$ & $\begin{array}{l}\text { Ocultar la verdad para } \\
\text { lograr un bien }\end{array}$ \\
\hline Sacrificio & $*$ & $*$ & $*$ & $*$ & Muestras de cariño \\
\hline Violencia & $*$ & $*$ & & $*$ & $\begin{array}{l}\text { Enojo, crítica hacia los } \\
\text { medios masivos de } \\
\text { comunicación }\end{array}$ \\
\hline
\end{tabular}

En la propuesta de Dragon Ball Z se expresan cuatro valores esenciales en los personajes y en la trama general del programa: la amistad, la ayuda al prójimo, la sabiduría y la violencia; esta última como la causa que desequilibra la armonía del universo y de la vida de los personajes.

La violencia, junto con la presentación de hechos sobrenaturales, es característica de las series televisivas japonesas de los noventa y de esta nueva década. Otro elemento significativo que caracteriza a los personajes de esta serie es, sin duda, el concerniente a las características biológicas o físicas de los protagonistas, como los superpoderes y el esfuerzo físico, características que no se presentan en los personajes de Los Simpson, ya que en ellos se manifiestan más las potencialidades y debilidades de los seres humanos comunes.

La propuesta valorativa detectada en el programa de Dragon Ball $Z$ se manifiesta fundamentalmente en los siguientes valores: 


\section{CUADRO 5 \\ CONCEPTUALIZACIÓN DE LOS VALORES ESENCIALES DE DRAGON BALL Z}

Valor

Forma en que se presenta

Amistad

Presente sobre todo en los momentos en que los personajes arriesgan la vida por sus compañeros y amigos.

Ayuda al prójimo Se manifiesta a través de ataques a favor de otros personajes, de los amigos o de la humanidad en general.

Sabiduría Consejos brindados por parte de los mayores a los pequeños luchadores, así como las acciones realizadas por los personajes después de actos de meditación.

Violencia Ataques entre los personajes, casi siempre a favor o en contra del bien o el mal.

Superpoderes Se refiere a las fuerzas y acciones que se escapan a la fuerza o inteligencia normal y suceden en las luchas entre los guerreros de la serie.

Esfuerzo físico La luchas entre los personajes duran más tiempo de lo normal, hasta el mismo concepto de éste es diferente, así como también los cuerpos de los propios guerreros.

La propuesta axiológica de este programa se define en lo general con pocos valores, pero con una definición dicotómica muy clara, donde sólo la sabiduría milenaria y los superpoderes o el esfuerzo físico que viene desde adentro - del espíritu- de los sujetos, están por arriba de lo positivo y lo negativo, expresados por la amistad y ayuda al prójimo contra la violencia que proviene de lo malo (ver Cuadros 5 y 6 ).

En esta producción japonesa es claro lo que Guillermo Orozco argumenta acerca de la posibilidad de "detectar algunos valores y antivalores distintivos de los dibujos animados, sobre todo cuando se trata de programas de aventuras/ficción. La propuesta axiológica parece centrarse en dos conjuntos de valores: los que resaltan la superioridad, ya sea tecnológica o racial, de los héroes y personajes centrales de los programas y aquéllos que se refieren a la forma de resolver el conflicto social" (Orozco, 1993:17).

Cabe recordar que las diferencias entre los primeros programas japoneses -como Mazinger Zo los caballeros del Zodíaco o Dragon Bally los de ahora se encuentran básicamente en las concepciones y maneras de expresar algunos significados que combinaban valores emanados de 


\begin{tabular}{|c|c|c|c|c|c|}
\hline \multicolumn{6}{|c|}{$\begin{array}{c}\text { CUADRO } 6 \\
\text { LOS VALORES GENERALES EN DRAGON BALL Z }\end{array}$} \\
\hline Valores & Individual & Grupal & $(+)$ & $(-)$ & $\begin{array}{c}\text { Emociones o actividades } \\
\text { que los reflejan }\end{array}$ \\
\hline Lo sobrenatural & $*$ & $*$ & $*$ & $*$ & $\begin{array}{l}\text { Transformación de cuerpos } \\
\text { Resurrección de la muerte } \\
\text { Viajes constantes al pasado } \\
\text { y al futuro }\end{array}$ \\
\hline Violencia & $*$ & $*$ & & $*$ & $\begin{array}{l}\text { Ataques } \\
\text { Luchas entre el bien } \\
\text { y el mal }\end{array}$ \\
\hline Amistad & & $*$ & $*$ & & $\begin{array}{l}\text { Arriesgar la vida por } \\
\text { compañeros } \\
\text { Apoyo moral a los amigos }\end{array}$ \\
\hline Ayuda al prójimo & $*$ & & $*$ & & $\begin{array}{l}\text { Defensa de amigos o de la } \\
\text { humanidad }\end{array}$ \\
\hline Sabiduría & $*$ & & $*$ & & $\begin{array}{l}\text { Consejos } \\
\text { Actos de meditación } \\
\text { Planteamientos de } \\
\text { estrategias y tácticas } \\
\text { de guerra }\end{array}$ \\
\hline
\end{tabular}

la cultura europea y se interpelaban desde los marcos culturales de los productores japoneses.

En las primeras producciones se formulaban posturas encontradas y dicotómicas entre los personajes, ya que todavía existía una fuerte influencia de la literatura europea y su expresión cultural (Alonso, Matilla y Vázquez, 1995); con Ranma y Medio, programa que se introdujo en nuestro país a mediados de los noventa, se presentaron los primeros cambios con la definición clara de algunos significados e interpretaciones venidas directamente del Japón, sin ninguna traducción cultural en los valores que representaban a los personajes protagónicos, tales como las que se expresaban en los comportamientos donde lo masculino yin y lo femenino yang formaban parte del mismo sujeto.

Por su parte, en Dragon Ball Z, los valores que expresan los personajes en sus discursos y sus acciones se entrelazan de manera tal que son cada vez más claros para los niños de occidente, puesto que conjugan 
una dicotomía entre buenos y malos donde, a pesar de que la mayoría de los personajes son inmortales y poco humanos, conjugan la maldad y la bondad según las circunstancias, sobre todo de conflicto. Al final de los episodios se establecen marcos donde la sabiduría, la cordura y la paz interior son la respuesta a los conflictos entre el bien y el mal.

En síntesis, los valores esenciales y generales de cada episodio de los dos programas presentan características que enmarcan las formas de vida de cada una de las culturas, las de EUA y Japón, desde donde se produce y ejerce una hegemonía en las estructuras de significado y valores que les permiten ubicarse como países centrales en el concierto global.

Hacer una triangulación entre la forma en que los niños reproducen un discurso político a partir de la información construida como reflejo de dos culturas diferentes a la propia resulta sumamente atractivo para este tipo de análisis; conocer cómo pueden ser entendidos y reproducidos los valores políticos venidos de una cultura que maneja concepciones de ser humanos y de situaciones de poder, diferentes de aquéllas con las que los niños mexicanos han convivido a través de experiencias directas, aportaría resultados significativos para entender los procesos de apropiación informativa realizados por las comunidades infantiles.

La anterior es una tarea que habrá de realizarse; sin embargo, es imprescindible conocer primero los diferentes significados políticos difundidos en los textos televisivos a diferentes niveles, es decir, como temáticas puntuales de lo político y como actuaciones de los personajes que hacen posible esa temática específica.

\subsection{La expresión política de los valores}

Resultaría complicado analizar la expresión axiológica en su dimensión política separada del marco general de los valores. La ayuda al prójimo, la amistad, la superación personal, la diversión, la desobediencia, el sacrificio, la violencia y hasta el amor son valores que conforman y son conformados por eventos políticos de los sujetos, tal como se explicó en la primera parte de los hallazgos del análisis de los programas televisivos. Delimitar con precisión hasta dónde entra la actuación política de los sujetos, o de los personajes para el caso del análisis realizado, y hasta dónde sus actos no están vinculados a prácticas de tal naturaleza, es una 
tarea titánica. Sin embargo, sí es posible reconocer e identificar aquellos valores que circulan de manera más directa en torno a las actuaciones políticas de los sujetos y de las representaciones que de éstos se realizan a través de los mensajes mediáticos.

De manera específica, los planteamientos actanciales (Greimas, 1993) de las series indican que los valores políticos propuestos por los programas analizados se pueden dividir en cuatro rubros importantes: poder y liderazgo; disfunción y corrupción política; Derechos Humanos y justicia social; $y$, por último, Política institucionalizada. Cada uno de ellos con una representación específica según el contexto, el momento y el personaje al que le toca representar dichos valores.

\section{A) Poder y liderazgo}

El poder, como una expresión natural y esencial de la política, está presente en las dos series analizadas. En Los Simpson, la búsqueda constante del control, del dominio y la influencia sobre los demás se presenta en todos los capítulos. Siempre algunos de los miembros de la familia tratan de ser los ganadores a partir de sus intereses particulares, solamente en pocas ocasiones se ponen de acuerdo varios miembros o todo el grupo familiar para resolver o llevar a cabo acciones que les otorgarán un beneficio común. En el programa de Dragon Ball Z, la lucha por el poder forma parte central de la trama, y tanto los buenos como los malos esto depende de los gustos particulares de los niños y de las reglas de la moralidad-siempre están buscando el poder, traducido en felicidad, amor, dominio de territorios, de espacios o de otros personajes.

En ambas series, el poder se centra en la ambición por conquistar un objetivo, objeto o persona. Existen momentos donde la ambición de los personajes les da resultados positivos; en algunos casos la plantean como aliciente interno del desarrollo del ser humano para conquistar metas inalcanzables. Sin embargo, en la mayoría de las situaciones, la ambición se presenta como un valor de los malos por dominar a la familia, el mundo o el universo.

De manera paralela, el liderazgo forma parte del juego de los diferentes personajes. En el caso de Los Simpson es muy claro que este concepto, dentro del hogar, gira alrededor de Homero o March frente a sus hijos; en la escuela de Bart y Lisa, son los profesores o los directivos 
que ejercen la autoridad. Por lo general, sin importar si se trata del espacio familiar o escolar, se ridiculiza el rol de la autoridad, sobre todo la de tipo autoritario. Tal es el caso del liderazgo que ejerce Homero sobre su familia, en donde siempre termina solicitando el apoyo de todos los miembros para culminar con éxito el objetivo o la acción que estaba realizando. Pareciera que a través de la serie se tratara de desarrollar una concepción de crítica hacia el autoritarismo.

En el programa de Dragon Ball Z, el autoritarismo casi siempre se presenta en los personajes que están a favor del mal o de alguna acción que va en contra del grupo que en ese momento desempeña el papel de bueno. Lo autoritario se manifiesta como la superioridad física o de armamento, especialmente en los momentos de conflicto o lucha. A los malos no les interesa hacer trabajo de equipo o de coordinación, ya que entre ellos mismos se pelean por la supremacía del poder y el liderazgo que siempre recae en autoritarismo. Al igual que en Los Simpson, en esta serie se hace una crítica al autoritarismo, aunque de manera más velada, a través de metáforas o situaciones muy concretas.

El trabajo en equipo fue otro valor presente en los dos programas. En Dragon Ball $Z$ se manifiesta el trabajo que realizaban ambos equipos -buenos y malos- desde el momento de la preparación previa para las luchas, la realización de éstas y en algunos casos por el grupo de los buenos para coordinar eventos o acciones de diversión, de trabajo o de apoyo a alguno de los miembros de su equipo, especialmente en los casos de enfermedades. En Los Simpson, el trabajo en equipo forma parte de la actividad cotidiana de los diferentes personajes, pero se hace énfasis en los ambientes familiares y escolares. Este tipo de trabajo casi siempre se realiza en búsqueda de un objeto que representa la realización en algún aspecto de la vida de los personajes. Dicho de otra manera, mediante el trabajo en equipo siempre se obtiene una recompensa.

\section{B) Disfunción y corrupción política}

La disfunción política se presenta en los dos programas analizados, principalmente se vivifica en tres eventos que se repiten constantemente durante la trama: la corrupción, sólo presente en Los Simpson; el incumplimiento de reglas, identificado en ambas series y, por último, la destrucción o muerte de los personajes que se oponen ante el 
régimen o poder establecido y que hace aparición sobre todo en el caso de Dragon Ball Z.

La corrupción presente en Los Simpson se hace evidente en los diferentes personajes, incluyendo en la bebé Maggy, quien trata de sobornar continuamente a sus hermanos o padres. Para Bart, la corrupción forma parte de su vida: en todo momento quiere sobornar a las autoridades, a sus padres, maestros y, en algunos casos, a la policía comunitaria. En los personajes adultos de la serie, la corrupción forma parte de su vida cotidiana, tal como sucede en la vida real; se soborna a los agentes viales, a los policías o a cualquier otra autoridad. El asunto de la corrupción y el soborno se presenta sólo en el programa de Los Simpson, quizá como una reproducción que critica al sistema social de EUA.

El incumplimiento de reglas es otro valor que se repite en las dos series. En Los Simpson se refleja en Homero y en Bart; en el primero ante las autoridades comunitarias, empresariales y con sus amigos, y en el segundo se repite constantemente en la familia, la escuela y la comunidad, o bien, en los lugares que para el papá son casi sagrados (como la cantina, el club o las casas de descanso). En el caso de Dragon Ball Z, este antivalor se hace explícito en los momentos en que los luchadores no obedecen lo que su jefe, o alguien superior a ellos, les indica. En cualquiera de los dos casos, este tópico se expresa como crítica al mismo concepto del incumplimiento, donde al final las cosas no siempre resultan como se pensaron y en ocasiones terminan mal.

La destrucción es una de las formas más crueles de la disfunción política, ya que algunos personajes son destruidos por muertes cruentas y, en algunos casos, difíciles de entender. Las continuas luchas sostenidas entre los personajes, originadas casi siempre por la búsqueda del poder para aplicarlo en dirección del bien o del mal, siempre terminan en la muerte, en la aniquilación de los enemigos, en la destrucción de objetos queridos o de comunidades completas.

\section{C) Derechos Humanos y Justicia social}

Como contraparte a la disfunción política, la corrupción y el abuso de la fuerza y el poder en el programa Los Simpson, se proponen los conceptos de defensa de los derechos humanos y del reclamo ante las injusticias sociales. 
El reclamo ante las injusticias sociales ejercidas por las autoridades y por los más fuertes forma parte del discurso de los personajes y se manifiesta mediante mítines, foros o cartas redactadas como respuesta al abuso de las autoridades o de algún miembro conflictivo de la familia. Contra el abuso de padres violentos, borrachos pendencieros y autoridades corruptas, existe el reclamo y la venganza como formas de resolver el daño físico o psicológico de los personajes.

La justicia se enarbola como el principal valor ante este mundo de injusticias para el caso de Los Simpson, y del universo en general para los personajes de Dragon Ball Z. Este planteamiento es utilizado para aplicar la normatividad objetivamente o para que uno de los personajes actúe bondadosamente en la resolución de algunos de los problemas de la trama. La justicia de Dragon Ball $Z$ se encuentra en cada uno de los protagonistas buenos, en su lucha y búsqueda del bien, pues uno de sus objetivos es hacer el bien justamente, ya sea para alguien más o para la humanidad en general.

Así, la tolerancia se presenta en los dos programas, aunque matizada en forma diferente. En Los Simpson se presenta cuando Homero tiene que sucumbir ante la inteligencia y chispa de Bart. En Dragon Ball Z, casi siempre los personajes más racionales tienen que expresar este valor ante los menos racionales, muchas veces justificado bajo los argumentos sentimentales.

La liberación femenina aparece como un valor agregado a la justicia y a la tolerancia y como un concepto contemporáneo de la sociedad estadounidense reproducida por Los Simpson, aunque en una forma de ridiculización. Ejemplo de ello son los actos de rebeldía vivificados por March y Maggy a favor de la liberación femenina. Este mismo planteamiento lo observaron Alonso, Matilla y Vázquez (1995) en un análisis de programas infantiles, donde el rol social de la mujer se reafirmaba con el tipo de trabajo que realizaban los personajes femeninos en los diferentes programas.

\section{D) Política institucionalizada}

La política institucionalizada se hace presente en Los Simpson como un valor expresado en diferentes eventos y protagonismos de los principales personajes. Este valor se refiere a la política reconocida y aceptada 
oficialmente y que se ubica en los espacios del Estado, de la escuela o en ciertas escenas en las que algunos miembros de la familia Simpson votan por alguien para ocupar la coordinación del barrio, del salón de clases o de los candidatos de Springfield.

Un programa de la serie es dedicado a la Política institucionalizada; a través de éste se presenta un proceso de elecciones presidenciales en Springfield. Se da a conocer un grupo de candidatos con todo y sus defectos, así como las estrategias de la mercadotecnia política que utilizan para ganar los cargos de elección popular, desde la realización de debates, desarrollo de la propaganda política, hasta el cierre del proceso de elecciones.

El Liberalismo, como filosofía, se pone en entredicho en este programa en el momento en que algunos personajes como Bart y Lisa se oponen a la forma en que se viven las elecciones en su ciudad. En otras escenas, Homero y March ridiculizan con sus formas de conducta y de vida el concepto liberal de mercado y de hacer política por parte de las autoridades oficiales. De esta manera, los diferentes personajes de Los Simpson, al burlarse de las reglas establecidas, se convierten en una especie de parodia para ridiculizar al sistema político y económico del liberalismo estadounidense.

La competencia, vista como una forma de expresión del liberalismo económico, es otro de los valores que se representan en tan singular familia, sobre todo en aquellas acciones de los personajes que muestran la rivalidad para vencer al otro. En Dragon Ball Z, la competencia forma parte del eje central en el que se expone la actual filosofía japonesa de mercado, se identifican diferentes comportamientos de rivalidad de los protagonistas en su afán por superar a los contrincantes, sean buenos o malos.

La competencia y la rivalidad son temas centrales en este tipo de géneros (Orozco, 1993). El maniqueísmo, en lo que se refiere al significado de la competencia, es una forma distintiva de los dibujos animados: la lucha por conseguir objetos preciados, el rescate de los amigos o de mujeres que fueron raptados por los malos o la conquista de espacios o lugares propios. "En los dibujos animados siempre hay personajes diferenciados por sus talentos, posesiones o amigos que los respaldan" (Orozco, 1993:17) y son el eje principal alrededor del cual giran las rivalidades o competencias de los protagonistas. 
Como elemento importante de esta rivalidad que prevalece en ambos programas se expone el concepto de creación de alianzas bajo distintas formas: realizar negociaciones entre los personajes a partir de sus intereses, mejorar sus grupos o vencer a la competencia. Cada vez más se presenta en este género la aceptación hacia las alianzas aun entre los buenos y algún grupo de malos con la finalidad de vencer la maldad (sobre todo en el programa japonés de Dragon Ball Z).

Por último, un tema por demás contemporáneo que se introduce en Los Simpson es, sin duda, el referente al poder de los medios masivos de comunicación y de manera particular el de la televisión. Los personajes de este programa, al ser asiduos televidentes como todo buen estadounidense -cuando menos visto por Matt Groening-, critican el contenido de lo que se expone en la televisión, ridiculizando el manejo psicológico y mercadotécnico que hacen de los receptores, sobre todo en periodos de elecciones.

\section{UNA REFLEXIÓN FINAL...}

Con frecuencia a la televisión se le ha vinculado con intereses económicos e ideológicos y, por lo menos en nuestro país, muy poco se le ha relacionado con el desarrollo de las culturas políticas. Los avances tecnológicos que la televisión ha tenido en el terreno de la información y producción audiovisual durante los últimos años son sorprendentes, por lo que no se puede comparar con el rol que desempeñan otros medios de comunicación, como la radio o la prensa, en la formación política de los sujetos. Su relación con las telecomunicaciones, la informática y la potencialidad del mensaje audiovisual ha venido engendrando cualidades que la tornan radicalmente diferente: su carácter simbólico y su constante adaptación inteligente a las necesidades de los dueños de los mensajes y de los públicos es, sin duda, una interrogante que habrá que responder en futuros estudios.

Entender el texto televisivo como partícipe de la constitución de culturas políticas específicas y de los procesos de aprendizaje político en diferentes públicos, pero sobre todo de los niños, es una tarea emergente. Considerar al texto televisivo como un factor de culturización política, después de que se le ha dado un peso importante a otros agentes 
a partir de diferentes momentos históricos, actualiza el juego de relaciones de poder entre ellos. Así, familia-Iglesia y familia-escuela han venido sucumbiendo ante la fórmula familia-escuela-televisión.

El texto televisivo, por tanto, se ha convertido en uno de los instrumentos de culturización más importante de la historia de la humanidad, al proponer marcos axiológico-políticos con mayor poder de fascinación y de penetración. Así, el texto televisivo propone estructuras de significados políticos; expone esquemas de valores, de pensamiento y de acción política, en breve participa en la constitución de culturas políticas.

El contenido de las series o géneros televisivos caricaturizados implica un complejo conjunto de mensajes, imágenes y significados construidos y colocados en el sistema televisivo para que los receptores los reciban, los consuman y los usen en su práctica social cotidiana. Será pues la propuesta axiológica política televisiva el principal instrumento para la formación política de los niños actuales, futuros votantes y posibles ciudadanos de una sociedad cada vez más politizada. Este trabajo sólo muestra una dimensión del complejo proceso de culturización a partir de la proposición de valores políticos expresados en el texto televisivo de las series caricaturizadas.

A pesar de los puntos coincidentes de los dos programas analizados, refiriéndonos a las cuestiones de fondo sobre la concepción y presentación de los valores políticos, se identifica en cada una de las series formas diferentes de presentar la política: en Los Simpson se puede apreciar un discurso analítico y de crítica social que, de manera explícita, sugiere la reflexión sobre la lógica de las situaciones políticas presentes en nuestra sociedad, sean éstas institucionalizadas o no; por su parte, Dragon Ball $Z$ presenta un discurso e imagen más sublime respecto al mismo tópico, que se relaciona más con la política individual manejada por los personajes según sus condiciones de poder, un discurso más independiente de las cuestiones sociales como algo institucionalizado, y más relacionado con decisiones de tipo personal, moral y humano.

Cada uno de los programas, desde su contexto y visión del mundo, ofrece y exige la promesa de una cultura política que añora una sociedad democrática, participativa y colaborativa, con sujetos conscientes de su ser y quehacer político. 


\section{BIBLIOGRAFÍA}

ALONSO, M., Matilla, L. y Vázquez (1995) Teleniños públicos, Teleniños privados. España: ediciones de la Torre.

ÁlVAREZ, Rosa (1999) La comedia enlatada, De Lucille Ball a Los Simpson. España: Gedisa.

BERELSON, Bernald (1952) Content analysis in Communications Research. Nueva York: Free Press.

BOURDIEU, Pierre (1997) Sobre la televisión. Barcelona, Anagrama.

BUONANNO, Milly (1999) El drama televisivo, identidad y contenidos sociales. España: Gedisa editorial.

CONTRERAS, Miguel y García, Agustín (1979) “El montaje como factor de análisis del telefilm”, en revista Mensaje y Medios, No. 6, enero.

ENLACE (1998) La familia, valores y autoridad, Vol. II, Trillas, México.

FABIÁN, Daniel (1997) "La construcción de los espacios televisivos infantiles españoles y argentinos", en revista Oficios terrestres. Argentina: Universidad de la Plata.

GARCÍA Nebrera, B. (1994) "El contenido de la programación infantil en televisión”, en García B. (Coord.), Televisión. Niños y jóvenes. España:RTVV.

GIDDENS, Anthony (1995) La constitución de la sociedad, bases para la teoría de la estructuración. Argentina: Amorrortu Editores.

GREIMAS, Algirdas (1993) La semiótica del texto. España: Paidós.

IBARRA, Armando (2003) Televisión y socialización política de escolares en la Zona Metropolitana de Guadalajara. Tesis doctoral. México: Universidad de Guadalajara.

KRIPPENDORFF, Klaus (1997) Metodología de análisis de contenido, teoría y práctica. Barcelona: Paidós.

KUBEY, Robert y Csikszentmihalyi, Mihaly (1990) Television and the Quality of life. How viewing shapes everyday experience. New Jersey: Lawrence Erlbaum associates, publishers, Hillsdale.

OROZCO, Guillermo (1993) El mensaje de la televisión mexicana en los noventa: un análisis axiológico de la programación de los canales 2, 5, 9, 11 y 13. México: Universidad Iberoamericana.

SÁNCHEZ, Enrique (1995) "La agenda televisiva en Guadalajara”, en Crovi, D., Desarrollo de la industria audiovisuales en México y Canadá, Proyecto Monarca. México: UNAM.

- (1997) "Some of the challenges facing Mexican communication research on the threshold of a new millennium", en Mexican Journal of Communication, No. 3. México: Fundación Manuel Buendía.

VEYRAT-MASSON y Dayan, Daniel (1997) Espacios públicos en imágenes. España: Gedisa editorial.

Fecha de recepción: 27/08/2004. Aceptación: 19/11/2004. 